\title{
A SUPERCONDUCTING RF GUN CURRENT STATUS OF THE DROSSEL COLLABORATION
}

\author{
D. Janssen ${ }^{+}$, FZ Rossendorf, Germany \\ Bushuev, M. Karliner, S. Konstantinov, J. Kruchkov, O. Myskin, V. Petrov, I. Sedlyarov, \\ A. Tribendis, V. Volkov, BINP, Russia \\ P. vom Stein, H. Vogel, ACCEL Instruments, Germany \\ A. Matheisen, M. Pekeler, DESY, Germany \\ W. Sander, I. Will, MBI, Germany
}

\begin{abstract}
The Drossel collaboration [1] was established for the development a low emittance, high average current, $\mathrm{cw}$ electron injector [2] suitable for the ELBE project $[3,4]$. The injector is based on a photocathode rf gun with a superconducting cavity. A half-cell $1.3 \mathrm{GHz}$ superconducting niobium cavity incorporated with a normal conducting cathode unit was designed and produced to check the basic design concepts. Cold rf tests of the cavity at $\mathrm{T}=2 \mathrm{~K}$ were successfully carried out at DESY TTF. Now preparation of the necessary components for the beam tests is in progress.
\end{abstract}

\section{INTRODUCTION}

The Drossel collaboration between FZR and BINP started in 1996. Recently more organisations jointed the collaboration. The basic idea of the project is to combine high brightness of an $\mathrm{rf}$ gun with low rf losses of a superconducting cavity. A design of a $1.3 \mathrm{GHz}, 3+1 / 2$ cell $\mathrm{rf}$ gun was worked out. The geometry of the 3 full cells is based on the TESLA design [5] to simplify the production. The shape of the half cell is optimised. A $\mathrm{Cs}_{2} \mathrm{Te}$ photocathode placed at the half cell back wall will be activated by an ultraviolet laser. The photolayer will be deposited on the tip of an OHFC copper stem in a special preparation chamber. The stem can be then transferred to the cavity by a manipulator. It will require neither any vacuum break nor cavity warm up to change the cathode.

\section{HALF CELL PROTOTYPE}

A prototype of the gun based on a half cell niobium cavity was developed to test the design solutions and to prove the compatibility of a photocathode and a sc cavity.

\subsection{Design Considerations}

The half cell cavity (fig. 1) is somewhat simplified compared to the optimum one in order to use an available

+Email: janssen@fz-rossendorf.de

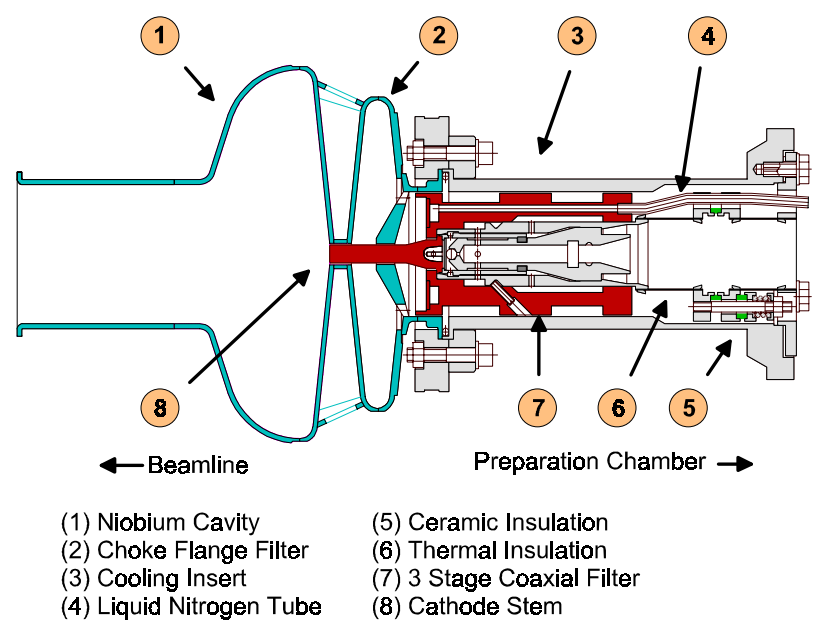

Fig. 1. Draft of 1/2 cell prototype.

TESLA endcup. Some parameters of the prototype cavity are listed in table 1.

Table 1. Prototype cavity parameters.

\begin{tabular}{|l|l|}
\hline Material & \\
\hline Cavity & Niobium (RRR > 250) \\
\hline Cathode Stem & OHFC Copper \\
\hline Operating Temperature & \\
\hline Cavity & $2 \mathrm{~K}$ \\
\hline Cooling Insert & $77 \mathrm{~K}$ \\
\hline RF Parameters & \\
\hline Frequency & $1300 \mathrm{MHz}$ \\
\hline Geometry Factor & $187.7 \mathrm{Ohm}$ \\
\hline $\mathrm{R}^{*}{ }^{*}$ & $120.5 \mathrm{Ohm}$ \\
\hline $\mathrm{H}_{\text {peak }} / \mathrm{E}_{\text {cath }}$ & $2.84 \mathrm{mT} /(\mathrm{MV} / \mathrm{m})$ \\
\hline $\mathrm{E}_{\text {peak }} / \mathrm{E}_{\text {cath }}{ }^{*} R / Q=U_{\text {gap }}{ }^{2} /\left(2 \cdot P_{\text {diss }} \cdot Q\right)$ \\
\hline
\end{tabular}

A key part of the design is a special cathode support structure. The photolayer deposited on a copper stem will operate at $77 \mathrm{~K}$. All the power dissipated in the cathode will be removed by $\mathrm{LN}_{2}$ neat exchanger attached to the cathode holder. The cathode holder is thermally and electrically isolated from the sc cavity and so causes only minimum additional heat load to the cavity and He bath. 
Rf power leakage from the cavity to the cathode holder is prevented by a niobium choke flange filter accompanied with a normal conducting coaxial filter which is a part of the cooling insert.

\subsection{Cavity Preparation and Test Results}

A few micrometers was etched away from inner and outer surfaces of the welded cavity at BINP. Then the cavity received a rough chemical treatment at FZR. Approximately $100 \bullet$ was removed from the inner surface. The final preparation of the cavity to the tests, including baking at $800^{\circ} \mathrm{C}$, light 1:1:2 $\mathrm{BCP}$, high pressure rinsing and clean room assembling, was done at DESY. Two cold tests were carried out at DESY up to date. In the first run the cavity was tested without the cathode in it to evaluate the achievable gradient. A maximum surface field of $36.1 \mathrm{MV} / \mathrm{m}$ was reached limited by field emission (fig. 2). Because of a very weak coupling during the first test the emitter could not be processed. Prior to the second test the cavity received a light $\mathrm{BCP}$ and a high pressure rinsed again. An uncoated copper cathode stem

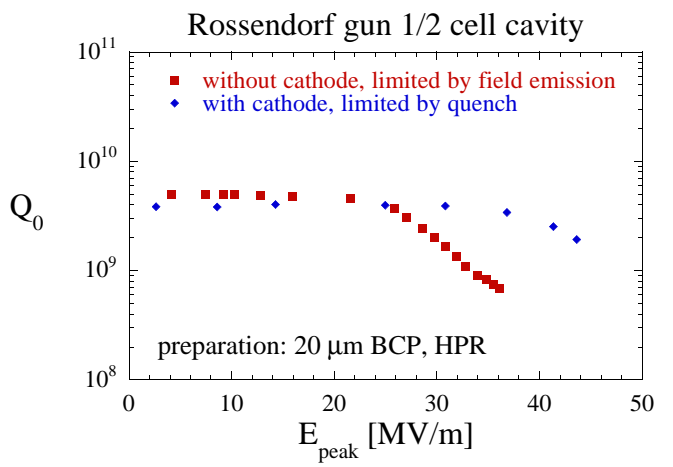

Fig. 2. Vertical test results.

was mounted directly to the cavity back flange using a special holder. In the second test the cavity reached a peak surface field of $43.6 \mathrm{MV} / \mathrm{m}$ which corresponds to a cathode field of $31.8 \mathrm{MV} / \mathrm{m}$. This time the maximum field was limited by a thermal break down (quench) at a peak magnetic field of $90.3 \mathrm{mT}$. The difference between the low field unloaded $\mathrm{Q}$ values is quite small, $5 \cdot 10^{9}$ to $4 \cdot 10^{9}$, which proves a very good performance of the choke flange filter.

\section{PREPARATION CHAMBER}

A photocathode preparation chamber has been designed and manufactured at BINP. First $\mathrm{Cs}_{2} \mathrm{Te}$ photolayers were prepared and tested with this chamber at FZR. The layers reached a quantum efficiency of $9 \%$ at a wavelength of $260 \mathrm{~nm}$. The light source was a Xenon lamp with a monochromatic filter. The initial value of the quantum efficiency decreased to $6 \%$ within 2 days and then kept unchanged for the following weeks.

\section{LASER}

Currently a pulsed laser system for activation of the photocathode is under construction at MBI, Berlin. The laser is a frequency quadrupled Nd:YLF laser operating in the ultraviolet range at $263 \mathrm{~nm}$. The laser shall provide a full synchronisation to the cavity rf with a time jitter of less than 3 ps. A pulse length of 4 to $7 \mathrm{ps}$ is projected. The laser is optimised for a quasi continuous operation. The average output power is 1 to $2 \mathrm{~W}$. The pulse repetition frequency can be chosen between $46.4 \mathrm{MHz}$ and the next two subharmonics.

\section{BEAM TESTS}

The next step is to prepare all the necessary equipment for the beam tests. The test set-up is shown in fig. 3 .

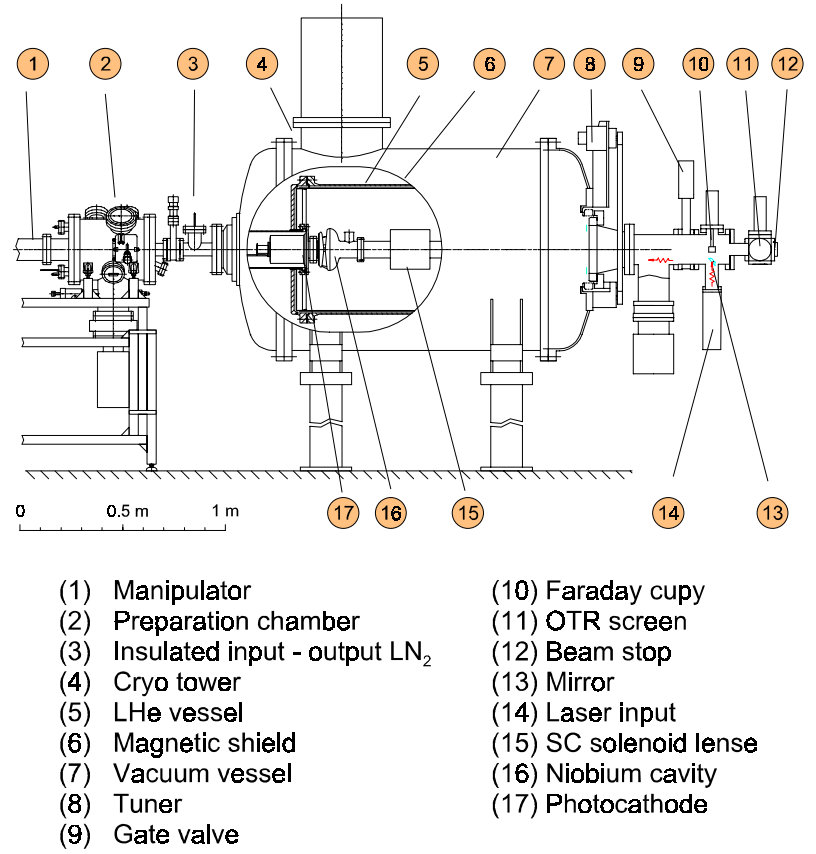

Fig. 3. Layout of the beam test set-up.

A horizontal cryostat is available from Stanford University. It is quite suitable for our needs after some modifications which will be made with help of ACCEL. The rf power source will be provided by FZR. The other parts, such as manipulator and gate valves, are commercially available. The beam tests are scheduled to the middle of the next year.

\section{ACKNOLEDGEMENTS}

We are pleased to thank the many colleagues who supported our work with their advice and helped us in our experiments. Special thanks to our colleagues from DESY for providing the vertical tests of our cavity. Also we wish to thank colleagues from TU Dresden for their help in cryogenic questions. 
Proceedings of the 1999 Particle Accelerator Conference, New York, 1999

\section{REFERENCES}

[1]D. Janssen et al., Proc. PAC 1997, p. 2838

[2]V. Volkov et al., Proc. PAC 1997, p. 2799

[3]F. Gabriel ed., FZR Internal Design Report, Dresden, 1995

[4]D. Janssen and P.vom Stein, Nucl. Instr.\&Meth., A380, 1996, p. 497

[5]D. Edwards, Tesla Test Facility - Design Report, DESY, Hamburg, 1995 